DOI: https://doi.org/10.24867/06BE04Djeric

\title{
SISTEM ZA PERSONALIZACIJU VIDEO TUTORIJALA ZASNOVAN NA MAŠINSKOM UČENJU
}

\section{VIDEO TUTORIAL PERSONALIZATION SYSTEM BASED ON MACHINE LEARNING}

\author{
Nevena Đerić, Fakultet tehničkih nauka, Novi Sad
}

\section{Oblast - SOFTVERSKO INŽENJERSTVO I INFORMACIONE TEHNOLOGIJE}

Kratak sadržaj - Problem koji ovaj rad rě̌ava jeste preporuka najpogodnijeg tipa tutorijala. Rad je rezultat istraživanja koje je rađeno nad studentima Fakulteta tehničkih nauka. Studenti su odgovarali na pitanja ankete, gledali video tutorijale o algoritmima sortiranja $i$ odgovarali na pitanja testa znanja o algoritmima sortiranja. Prilikom gledanja jednog od video tutorijala praćen im je pogled na ekranu uz pomoć uređaja za praćenje pokreta očiju. Na taj način formiran je skup podataka, koji je korišćen za izgradnju modela. U modelu sa najvećom tačnošću, za pronalaženje sličnih studenata koristi se KNN algoritam. Na osnovu sličnih studenata pronalazi se najpogodniji tip tutorijala za datog studenta. Ovaj model postigao je tačnost od $75 \%$ na validacionom skupu i tačnost od 67\% na testnom skupu.

Ključne reči: personalizovana nastava, eye-tracker uređaj, klasterovanje, KNN, KMeans

Abstract - The problem that this paper solves is the recommendation of the most appropriate type of tutorial to the student. This paper is the result of research conducted on students of the Faculty of Technical Sciences. Twenty nine students were questioned. Students answered survey questions, watched video tutorials on sorting algorithms, and answered questions about sorting algorithms. When they were watching one of the video tutorials, their eye movement were followed using an eyetracking device. In that way was formed dataset that was used to build the model. The model that gave the highest accuracy is consisted of KNN algorithm, which is applied in finding students with the most similar type of movement. The most appropriate type of tutorial is found based on similar students. This model achieved an accuracy $75 \%$ on the validation set and accuracy $67 \%$ on the test set.

Keywords: personalized teaching, eye-tracker device, clustering, KNN, KMeans

\section{UVOD}

Personalizovana nastava je nastava budućnosti. Razlike u psiho-fizičkim sposobnostima, načinima percepcije okruženja i stečenim navikama kod studenata rezultuju nejednakom efikasnošću usvajanja znanja. Prilagođavanje nastave pojedincu dovodi do boljih rezultata.

\section{NAPOMENA:}

Ovaj rad proistekao je iz master rada čiji mentor je bio dr Aleksandar Kovačević, red. prof.
Ovo potvrđuje i činjenica da studenti sve više uplaćuju privatne časove ili pretražuju internet, da bi pronašli reprezentaciju gradiva u željenom obliku [1]. Pitanje koje se postavlja je da li način učenja, koji student smatra da je optimalan za njega, stvarno dovodi do najboljih rezultata u najkraćem vremenskom periodu.

U ovom radu opisan je sistem za preporuku najpogodnijeg video tutorijala. Sistem vrši preporuku na osnovu osobina studenta i njegovog tipa gledanja.

Rad sadrži šest sekcija. U drugoj sekciji prikazana su prethodna rešenja problema, koja u svojim istraživanjima koriste uređaj za praćenje pokreta očiju. U trećoj sekciji opisan je skup podataka, obeležja koja sadrži, način prikupljanja podataka i proces njegovog skladištenja. U četvrtoj sekciji opisani su korišćeni alati prilikom implementacije sistema i opisana je metodologija. U petoj sekciji opisana je evaluacija sistema. U šestoj sekciji izvršen je osvrt na implementirani sistem i prodiskutovani nedostaci sistema, kao i potencijalna buduća poboljšanja.

\section{PRETHODNA REŠENJA}

Tehnologija za praćenje pokreta očiju (engl. eye-tracking) je skup metoda i tehnika koje se koriste za detektovanje i snimanje aktivnosti pokreta očiju. Uređaj za praćenje pokreta očiju (engl. eye-tracker) meri pokrete očiju dok se oči kreću gledajući u neki video objekat [2]. Postoje razni radovi koji u svom istraživanju koriste uređaj za praćenje pokreta očiju, kao i neke od metrika za obradu podataka prikupljenih pomoću ovih uređaja. Njihov pregled dat je $u$ nastavku.

U objavljenim radovima koriste se različite metrike za praćenje pokreta očiju. Čak i kada se koristi ista metrika, u različitim radovima, drugačije se naziva. Posledica ovoga su teška poređenja studija. Postoji potreba za standardizacijom metrika koje se koriste za obradu podataka sa uređaja za praćenje pokreta očiju. Rad [3] nastoji da dovede do svesti za konzistentnom upotrebom ovih metrika. U radu dat je pregled metrika korišćenih u ostalim radovima. Metrike bazirane na fiksaciji očiju mogu se podeliti na metrike broja fiksacija i metrike trajanja fiksacija. Fiksacije su ona vremena kada oči prestaju da se pomeraju, drže pogled na jednom mestu, tako da vizuelni sistem može dobiti informaciju o tome šta ispitanik gleda. Fixation Rate spada u metrike broja fiksacija. Izračunava se kao odnos broja fiksacija područja od interesa i ukupnog broja fiksacija ili broja fiksacija nekog drugog područja od interesa. Fixation Time spada $\mathrm{u}$ metrike trajanja fiksacije. Predstavlja zbir trajanja svih fiksacija područja od interesa. Područje od interesa (engl. 
Areas of Interest - AOI) je alat za odabir područja za praćenje i izračunavanje metrika. Nije strogo merni alat sam po sebi, ali predstavlja područje na kojem se izračunavaju drugi merni podaci [4].

U radu [5] su korišćene metrike fiksacije: broj fiksacija za svako područje od interesa, ukupno vreme trajanja fiksacija, vreme prve fiksacije određenog područja od interesa. Predstavljena su dva eksperimenta. Prvi eksperiment predstavlja analizu opažanja u medicinskom procesu dijagnostikovanja. Drugi eksperiment predstavalja analizu vizuelne pažnje pacijenata prilikom pshiomotonog testa. Za praćenje pokreta očiju u ovom istraživanju korišćen je ekranski uređaj. Da bi prikazali razliku između radiologa eksperta i studenta korišćene su toplotne mape. Toplotna mapa (engl. heatmap) predstavlja grafički prikaz frekvencije gledanja pojedinačnih delova ekrana. Delovi se označavaju određenom bojom, zavisno od broja identifikovanih fiksacija oka. Tako se crvenom bojom označavaju delovi koji su privukli najviše pažnje korisnika, nakon koje slede narandžasta, žuta, pa plava boja kojom su označeni delovi sa najmanjim brojem fiksacija [4].

Rad [6] opisuje klasterovanje podataka dobijenih pomoću uređaja za praćenje pokreta očiju. Korišćeni algoritmi klasterovanja su: KMeans, spectral clustering i DBscan. Predloženi pristup za evaluaciju konfiguracije klastera sastoji se od dva koraka.

Prvi je primena interne mere validacije klastera, koja se zove koeficijent siluete (engl. silhouette score) [7]. Nedostatak ove mere jeste favorizovanje konveksnih klastera, što možda ne odgovara strukturi podataka.

Drugi korak jeste vizuelizacija rezultata klasterovanja. Metode redukcije dimenzionalnosti projektuju podatke visokih dimenzija u ljudski čitljiv dvodimenzionalni prostor. U ovom radu koristi se t-SNE ( $t$-Distributed Stochastic Neighbor Embedding) [8]. Algoritam može otkriti strukturu podataka, ali se ne može koristi za klasterovanje, jer ne čuva udaljenost.

Još jedan rad [9] bavi se pronalaženjem korelacije između načina gledanja kod ljudi i njihovih osobina. Konkretno, dokazuje različitost muškaraca i žena u načinu posmatranja slika. Snimani su pokreti očiju 52 osobe starosti od 19 do 47 godina prilikom njihove evaluacije $u$ tri različite dimenzije značenja 80 različitih slika. Rezultati pokazuju da su dužine fiksacija kod muškaraca kraće nego kod žena, dok su amplitude brzog pomeranja oka kod žena znatno veće nego kod muškaraca. Pokazano je da su žene sklonije istraživanju, praveći više fiksacija van regiona lica a slikama. Tačnost kojom je u ovom radu klasifikovan pol osobe na osnovu gledanja jedne slike iznosi $63 \%$.

\section{OPIS SKUPA PODATAKA}

Skup podataka za ovo istraživanje prikupljen je ispitivanjem studenata. Ispitano je 29 studenata, prosečne starosti 20 godina. Svaki student je popunjavao anketu, koja se sastoji od pitanja kao što su koliko često gleda tutorijale, koliko dugo mu gledanje tutorijala ili čitanje drži pažnju, itd, kao i pitanja koja se tiču njegovog prethodnog obrazovanja, pola, mesta rođenja, godina, itd. Nakon popunjavanja ankete student gleda tri video tutorijala. Tutorijali su pravljeni tako da poseduju različite elemente: tutora, animaciju i prevod. Uvodni video tutorijal sadrži sva tri elementa. Prilikom gledanja ovog tutorijala studentu se prati pogled na ekranu. Nakon odgledanog tutorijala, student gleda još dva tutorijala $\mathrm{u}$ vezi dva algoritma sortiranja: Bubble sort [10] i Selection sort [11]. Za svaki algoritam postoje četiri kombinacije (sa tutorom sa prevodom, bez tutora (animacija) sa prevodom, sa tutorom bez prevoda, bez tutora bez prevoda). Student za svaki algoritam gleda jednu kombinaciju. Posebno je obraćena pažnja da se studentu ne pusti ista kombinacija za oba algoritma. Nakon odgledanih tutorijala student odgovara na pitanja testa znanja o prezentovanom algoritmu sortiranja.

Od studentovih odgovora na pitanja ankete i testa, kao i od podataka prikupljenih pomoću uređaja za praćenje pokreta očiju formiran je skup podataka. Prikupljeni podaci se mogu podeliti u tri celine: podaci sa ankete, podaci prikupljeni pomoću uređaja za praćenje pokreta očiju i podaci sa testa znanja. Podaci sa ankete i podaci sa testa se čuvaju u CSV datoteci. Za svakog studenta čuva se vektor obeležja. Podaci praćenja pokreta očiju prikupljeni su uz pomoć softvera za upravljanje uređajem za praćenje pokreta očiju. Ovaj softver za svakog studenta generiše CSV datoteku u koju se za svaki sekund trajanja videa izgeneriše po 60 vektora.

\section{METODOLOGIJA I ALATI}

U ovoj sekciji opisani su alati korišćeni za implementaciju sistema i prikazana je metodologija.

\subsection{Korišćeni alati}

U ovom istraživanju koristi se Gazepoint GP3 eye-tracker [12] ekranski uređaj. Softver koji se koristi za upravljanje uređajem za praćenje pokreta očiju, kao i za prikupljanje i obradu prikupljenih podataka je Gazepoint Control and Analysis [13]. Za implementaciju sistema koristi se programski jezik Python [14].

\subsection{Metodologija}

Metodologija ovog rešenja može se podeliti u tri celine: obrada i analiza podataka, pronalaženje studenata sa najsličnijim tipom gledanja i uspostavljanje korelacije između osobina gledanja i rezultata testa znanja.

\subsubsection{Obrada i analiza podataka}

Ova podsekcija opisuje proces obrade i vizuelizacije podataka.

Podaci sa ankete sadrže kategorijske vrednosti. Kategorijske vrednosti zamenjene su numeričkim pomoću metode Label encoding [15]. Vrednost atributa mesto rođenja zamenjena je sa brojem stanovnika u tom mestu. Ovo je urađeno kako bi se napravila razlika između malih i velikih mesta.

Podaci sa uređaja za praćenje pokreta očiju obrađeni su pomoću metrika za obradu podataka prikupljenih pomoću uređaja. Za svako područje od interesa (tutora, animaciju i prevod) računata je Fixation rate metrika, kao odnos broja fiksacija područja od interesa i ukupnog broja fiksacija. Fixation Time metrika predstavlja ukupno vreme fiksacija područja od interesa. Vreme prve fiksacije 
područja od interesa predstavlja vreme koje je studentu potrebno da prvi put ugleda područje od interesa.

Odgovori studenata na pitanja sa testa znanja zamenjeni su sa brojem poena. Svaki tačan odgovor vrednovan je sa jednim poenom. Prilikom računanja broja poena u obzir je uzeto $\mathrm{i}$ vreme koje je bilo potrebno da se odgovori na pitanje. Na svaki poen tačnog odgovora dodat je i koeficijent, brzine davanja tačnog odgovora, koji je računat prema formuli $\frac{10}{t}$, gde je t broj sekundi koji je bio potreban studentu da odgovori na pitanje. Analizom skupa podataka ova formula je odabrana kao najpogodnija da napravi razliku između brzine potrebne za odgovor na pitanje.

Prikupljeni podaci su visoko dimenzionalni. Da bi se ovakav skup podataka mogao vizuelizovati najpre bi trebalo primeniti neku od metoda za redukciju dimenzionalnosti. $\mathrm{Na}$ slici 1. prikazana je vizuelizacija redukovanih podataka sa ankete pomoću t-SNE algoritma. Na slici se može primetiti izdvajanje četiri klastera. Brojevi pored tačaka su jedinstveni identifikatori studenata. Brojevi pored grupa tačaka predstavljaju brojeve klastera. Studenti prvog klastera su muškarci, koji često gledaju video tutorijale i pohađali su srednju tehničku školu. Studenti drugog klastera su muškarci, koji provode više od 4 sata dnevno na internetu i više vole da čitaju kraće forme, kao što su časopisi ili novine. Studenti trećeg klastera nemaju iskustva u programiranju i više vole da čitaju knjige i gledaju filmove. Četvrtom klasteru pripadaju studentkinje, koje imaju po 19 godina i ne bave se sportom.

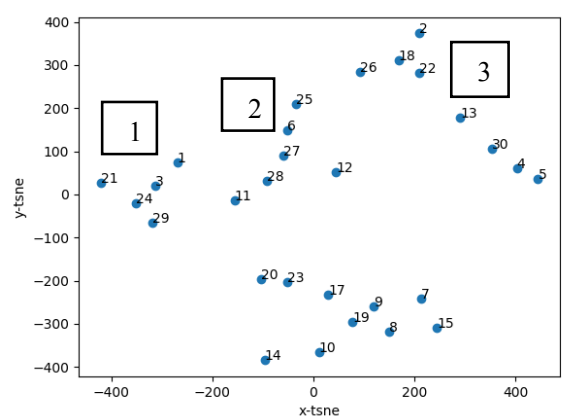

Slika 1. Vizuelizacija skupa podataka sa ankete

Na preprocesirane podatke dobijene pomoću uređaja za praćenje pokreta očiju primenjen je PCA (Principal Component Analysis) [16] algoritam za redukciju dimenzionalnosti. Na tako redukovane podatke primenjen je KMeans algoritam za klasterovanje. Pomoću lakatnog metoda i koeficijenta siluete za $k$ je dobijen broj 4 . Za inicijalizaciju centara klastera korišćen je KMeans ++ algoritam. Na slici 2. prikazano je klasterovanje studenata prema tipu gledanja. Za svaki klaster izgenerisane su toplotne mape, koje su prikazane na slici 3. Toplotna mapa 3. a prikazuje studente koji pripadaju prvom klasteru. Može se primetiti da su studenti ovog klastera pratili pogledom podjednako animaciju i tutora, takođe su gledali i prevod, ali znatno manje nego animaciju i tutora. Toplotna mapa 3. b prikazuje studente koji pripadaju drugom klasteru. Ovi studenti su najviše pažnje obraćali na animaciju. Toplotna mapa 3. c prikazuje studente trećeg klastera. Ovi studenti su najviše gledali u tutora. Toplotna mapa 3. d prikazuje studente četvrtog klastera. Ovaj klaster predstavlja šum, odnosno u njega su svrstani studenti kojima uređaj za praćenje pokreta očiju nije uspeo da isprati pogled, npr. pomerili su se prilikom gledanja video tutorijala i uređaj za praćenje pokreta očiju nije detektovao oči.

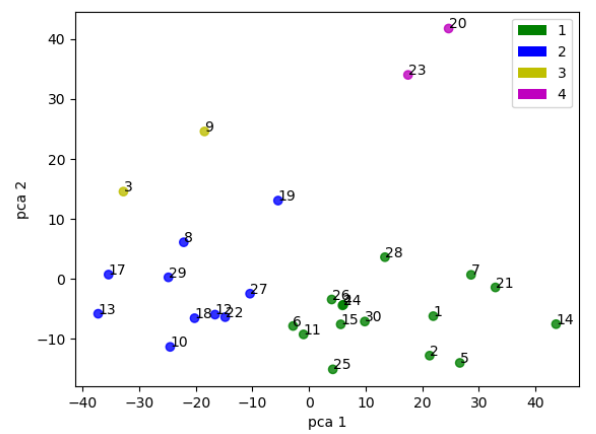

Slika 2. KMeans klasterovanje studenata na osnovu metrika za praćenje pogleda

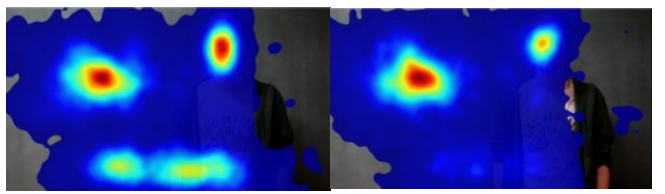

a

b

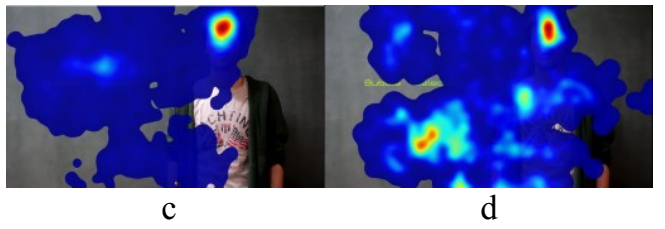

Slika 3 Prikaz toplotne mape studenata koji pripadaju redom prvom, drugom, trećem i četvrtom klasteru

\subsubsection{Pronalaženje studenata sa najsličnijim tipom gledanja}

Za pronalaženje studenata sa najsličnijim tipom gledanja upotrebljeni su podaci sa ankete i podaci sa uređaja za praćenje pokreta očiju obrađeni pomoću metrika.

Na preprocesirane podatke primenjen je KNN (K Nearest Neighbors) [17] algoritam. KNN algoritam je efikasan u rešavanju sličnih problemima, pa je izabran da se koristi $u$ ovom sistemu. Algoritam za prosleđenog studenta pronalazi studente sa najsličnijim tipom gledanja.

\subsubsection{Uspostavljanje korelacije između osobina gledanja i rezultata testa znanja}

Ova metoda određuje optimalan tip gledanja za prosleđen skup studenata. Bubble i Selection sort algoritmi posmatraju se kao ekvivalentni. Za svakog studenta iz skupa posmatra se razlika u tipu, odnosno kombinaciji elemenata, odgledanih video tutorijala. Na primer, ako je student ostvario više poena na testu video tutorijala, koji je sadržao tutora, ali nije imao prevod, nego na testu video tutorijala, koji nije sadržao tutora, ali jeste imao prevod, može se zaključiti da studentu, tutor pomaže u učenju, dok sa prevodom to nije slučaj. Na ovaj način, dodeljivanjem pozitivnih i negativnih bodova vezanih za posto- 
janje elementa u video tutorijalu dolazi se do ukupnih bodova. Bodovi upućuju na tip tutorijala, koji je optimalan za prosleđeni skup studenata. Pošto prosleđeni studenti imaju najsličnije osobine sa studentom za kog se traži odgovarajući tip tutorijala, onda je taj tip tutorijala optimalan za tog studenta. Osim pronalaska optimalnog tipa tutorijala, iz ovih podataka se mogu rangirati i ostali tipovi tutorijala. Krajnji rezultat ove metode je lista tipova tutorijala sortirana od najpogodnijeg do najmanje pogodnog za datog studenta.

\section{EVALUACIJA I REZULTATI}

U ovom istraživanju performanse su evaluirane na dva načina. Prva evaluacija urađena je podelom skupa podataka na obučavajući i testni. Obučavajući skup podataka sadrži $80 \%$ podataka, a testni $20 \%$. Podaci iz testnog skupa nisu se ni na koji način koristili prilikom obučavanja. Druga evaluacija urađena je samo na obučavajućem skupu, pomoću unakrsne validacije (engl. crossvalidation) sa 4 podskupa. Za metriku je korišćena tačnost (engl. accuracy). Za izračunavanje tačnosti upoređeni su tipovi tutorijala koje je sistem predložio sa tipovima koje je student gledao. Student je odgledao samo dva od moguća četiri tipa. Zbog toga se ne gleda samo najpogodniji tip, nego se uzima u obzir lista sortiranih tipova od najpogodnijeg do najmanje pogodnog. Porede se poeni koje je student osvojio na testu znanja i gleda se mesto koje tip odgledanog video tutorijala zauzimaju na listi predloženih. Ukoliko je tip tutorijala, za koji je student dobio više poena, na listi pre tipa za koji je student dobio manje poena znači da je model dao dobru preporuku. Najveća tačnost od $75 \%$ dobijena je na validacionom skupu sa izborom 5 suseda. Dok tačnost na testnom skupu iznosi $67 \%$.

\section{ZAKLJUČAK}

U ovom radu predstavljen je sistem za personalizaciju video tutorijala. Sistem za unete podatke sa ankete za studenta i podatke dobijene pomoću uređaja za praćenje pokreta očiju prilikom gledanja uvodnog tutorijala pronalazi najpogodniji tip tutorijala.

Model koji je dao najbolje rezultate za pronalaženje najsličnijih studenata koristi KNN algoritma. Na osnovu sličnih studenata pronalazi se odgovarajući tip tutorijala za datog studenta. Ovaj model je postigao tačnost od $75 \%$ na validacionom skupu i tačnost od $67 \%$ na testnom skupu, što znači da je sistem uspešan za četiri od šest slučaja. Može se smatrati dobrim rezultatom, s obzirom na količinu prikupljenih podataka.

Prikupljanje podataka za ovo istraživanje je predstavljalo najveći izazov. Osnovni problem je bio motivisati studente da učestvuju u ovom istraživanju. Sa druge strane, postoji jedan uređaj za praćenje pokreta očiju, pa se prikupljanje podataka ne može optimizovati, niti paralelizovati. Ispitivanje je vršeno u laboratorijski kontrolisanim uslovima, koje zahteva dosta vremena.

Sledeći korak u uvođenju personalizovane nastave bi bilo proširivanje istraživanja van okvira laboratorije. Za to bi se mogli iskoristiti pametni telefoni i tableti, kao uređaji za praćenje pokreta očiju [18]. Sledeći korak unapređenja sistema je implementacija mobilne aplikacije za prikupljanje podataka $\mathrm{u}$ realnom vremenu. Prilikom prikupljanja velike količine podataka javljaju se drugi problemi, koji se mogu otkloniti pomoću alata za obradu velike količine podataka.

\section{LITERATURA}

[1] Milena Kostadinović. Personalizacija obrazovanja (Stilovi učenja), 2015

[2] Mele, Maria Laura, and Stefano Federici. Gaze and eye-tracking solutions for psychological research. Cognitive processing, 2012, 13.1: 261-265.

[3] Sharafi, Zohreh, et al. Eye-tracking metrics in software engineering. In: 2015 Asia-Pacific Software Engineering Conference (APSEC). IEEE, 2015. p. 96-103.

[4] https://imotions.com/blog/7-terms-metrics-eye-tracking/ (pristupljeno u avgustu 2019.)

[5] Borys, Magdalena, and Małgorzata Plechawska-Wójcik. Eyetracking metrics in perception and visual attention research. EJMT, 2017, 3: 11-23.

[6] Göbel, Fabian, and Henry Martin. Unsupervised Clustering of Eye Tracking Data. In: Spatial Big Data and Machine Learning in GIScience, Workshop at GIScience 2018. p. 25-28.

[7] Rousseeuw, Peter J. Silhouettes: a graphical aid to the interpretation and validation of cluster analysis. Journal of computational and applied mathematics, 1987, 20: 53-65.

[8] Maaten, Laurens van der; HINTON, Geoffrey. Visualizing data using t-SNE. Journal of machine learning research, 2008, 9.Nov: 2579-2605.

[9] Moss, Felix Joseph Mercer, Roland Baddeley, and Nishan Canagarajah. Eye movements to natural images as a function of sex and personality. PLoS One, 2012, 7.11: e47870.

[10] Astrachan, Owen. Bubble sort: an archaeological algorithmic analysis. In: ACM SIGCSE Bulletin. ACM, 2003. p. 1-5.

[11] Hayfron-Acquah, J. B., Obed Appiah, and K. Riverson. . Improved Selection Sort Algorithm. International Journal of Computer Applications, 2015, 110.5.

[12] https://www.gazept.com/product/gazepoint-gp3-eye-tracker/, (pristupljeno u avgustu 2019.)

[13] https://www.gazept.com/tutorials/, (pristupljeno u avgustu 2019.)

[14] https://www.python.org/, (pristupljeno u avgustu 2019.)

[15] https://towardsdatascience.com/choosing-the-right-encodingmethod-label-vs-onehot-encoder-a4434493149b, (pristupljeno u avgustu 2019.)

[16] Wold, Svante, Kim Esbensen, and Paul Geladi. Principal component analysis. Chemometrics and intelligent laboratory systems, 1987, 2.1-3: 37-52

[17] Peterson, Leif E. K-nearest neighbor. Scholarpedia, 2009, 4.2: 1883.

[18] Krafka, Kyle, et al. Eye tracking for everyone. In: Proceedings of the IEEE conference on computer vision and pattern recognition. 2016. p. 2176-2184.

\section{Kratka biografija:}

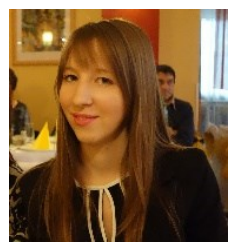

Nevena Đerić rođena je 05.06.1995. godine u Užicu. Osnovnu školu ,Prva osnovna škola kralj Petar Drugi“" završila je 2010. godine. Gimnaziju ,Užička gimnazija“ u Užicu, prirodno-matematički smer, završila je 2014. godine. Iste godine upisala se na Fakultet tehničkih nauka, odsek Računarstvo $\mathrm{i}$ informatika. Zvanje diplomirani inženjer elektrotehnike i računarstva stekla je 2018. godine. Iste godine upisala je master akademske studije na smeru Softversko inženjerstvo $\mathrm{i}$ informacione tehnologije. Uža specijalnost na master studijama joj je inteligentni sistemi. Položila je sve ispite propisane planom i programom. 